Alma Mater Studiorum - Università di Bologna DEPARTMENT OF ECONOMICS

\title{
On Prices' Cyclical Behaviour in Oligopolistic Markets
}

\author{
Luca Lambertini
}

Luigi Marattin

Quaderni - Working Paper DSE Nº64

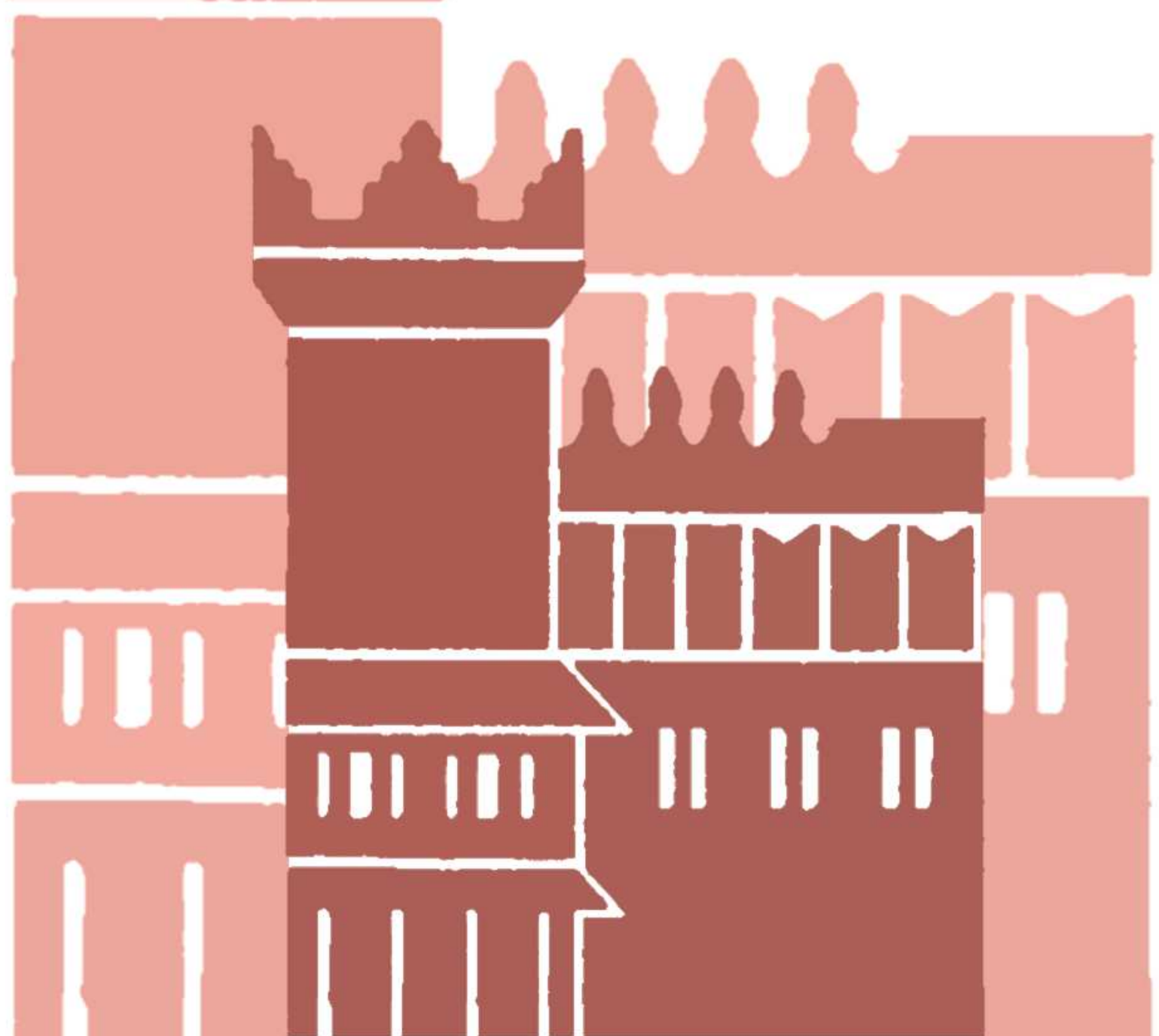




\title{
On Prices' Cyclical Behaviour in Oligopolistic Markets*
}

\author{
Luca Lambertini and Luigi Marattin \\ Department of Economics, University of Bologna \\ Strada Maggiore 45, 40125 Bologna, Italy \\ luca.lambertini@unibo.it; luigi.marattin@unibo.it
}

April 22, 2016

\begin{abstract}
We revisit the discussion about the relationship between price's cyclical features, implicit collusion and the demand level in an oligopoly supergame where a positive shock may hit demand and disrupt collusion. The novel feature of our model consists in characterising the post-shock noncooperative price and comparing it against the cartel price played in the last period of the collusive path, to single out the conditions for procyclicality to arise both in the short and in the long-run.
\end{abstract}

JEL Codes: C73, E60, L13

Keywords: demand shocks, cyclical pricing, implicit collusion

*We would like to thank Giacomo Calzolari, Vittoria Cerasi, Matthew Wakefield, Gabriella Chiesa, Antonio Minniti and the audience at the Italian Economic Society Conference (Trento, 2014) and ASSET 2014 (Aix en Provence) for precious comments and suggestions on a previous draft that circulated under the title "Cartel Stability, Mark-up Cyclicality and Product Differentiation". Special thanks to Federico Etro. The usual disclaimer applies. 


\section{Introduction}

What are the cyclical properties of prices in a collusive oligopoly hit by a positive demand shock? In their seminal work, Rotemberg and Saloner (1986) argue that oligopolies are likely to behave more competitively when demand rises, especially when price is the strategic variable and the good is homogeneous. Under these circumstances, in fact, the benefit from deviation is larger, and the punishment is diminished because it will be implemented when the expansionary demand shock will have already been absorbed. As a results, pricing exhibits a countercyclical pattern when demand increases. In this paper we insert three main modifications into the above framework: i) the presence of product differentitation; ii) the possibility for firms to collude, after the occurrence of the demand shock, on virtually any price between the monopoly and the Nash equilibrium one; and iii) a specific role for two critical demand aspects: the state of demand before the shock hits the industry, and the size of the shock itself. We show that in the resulting framework the traditional Rotemberg and Saloner (R\&S) result no longer holds, and a procylical pricing pattern can emerge depending on $a$ ) the state of demand before the shock hits, and $b$ ) the size of the demand shock.

The three modifications to the standard R\&S framework that we put forward have been discussed separately in the literature. The role of demand's features has been investigated by Haltiwanger and Harrington (1991), who extend the R\&S analysis to allow for time-varying firms' expectations on future demand, by relaxing the assumption of i.i.d. demand shocks so as to induce serial correlation in the cycle. As a result, they highlight potential asymmetries in collusive pricing behavior across different state of the business cycle, as their findings show that collusion is more difficult during recessions than during booms. ${ }^{1}$ Along this path, Bagwell and Staiger (1997) develop a theory of collusive pricing in a framework where aggregate demand alternates stochastically between slow and fast growth periods, the transition

\footnotetext{
${ }^{1}$ Fabra (2006) shows that this result can be overturned if firms'capacities are sufficiently small. Along the same line, Knittel and Lepore (2010) show that if the marginal cost of capacity is high enough, prices in booms are generally lower than prices in recession.
} 
being governed by a Markov process. They find that the cyclical behaviour of collusive prices depends crucially on the correlation of demand growth rates over time and the expected duration of booms and recessions. In particular, collusive prices are procyclical in presence of positive demand correlation through time, and countercyclical otherwise. Furthermore, the amplitude of collusive pricing is larger when the recession has a longer expected duration or, conversely, when the boom phase is shorter.

Secondly, the effect of product differentiation on collusion has been widely investigated without accounting for the occurrence of demand shocks and taking the level of collusion as given, in most cases at the frontier of joint profits (see, among others, Deneckere, 1983; Majerus, 1988; Ross, 1992; Friedman and Thisse 1993; and Lambertini, 1997). Finally, the interplay between product differentiation and the intensity of collusion when shocks hit demand has been explicitly addressed by Colombo (2002) and Raith (1996). The first contribution adopts the same consumer utility function and therefore also the same demand structure as in our model but (i) restricts the analysis to full collusion and (ii) assumes a specific distribution for the demand shock over a finite and compact support, finding that under Cournot competition the likelihood of collusion increases when demand is high provided product differentiation is very high. The second, again referring to full collusion, uses instead a Hotelling model with stochastic demand to show that an increase in product differentiation leads to a decrease in the correlation of the firms' demand shocks. This, under imperfect monitoring, makes collusion more difficult to sustain because distinguishing the effects of random shocks and deviations from collusion becomes more difficult.

So far, in the attempt to assess the link between demand cycle and prices, these three aspects (demand shock features, product differentiation and intensity of collusion) have been treated separately. In this paper, we investigate how the they interact when inserted in the standard R\&S framework, when firms compete in differentiated oligopoly under both Bertrand and Cournot behaviour. In both settings, we compare the collusive price firms charge under two alternative demand states ("low" and "high") with the 
price charged after the occurrence of a positive demand shock affecting the high demand state and triggering the output cyclical movement.

Our results show that in such a framework the traditional countercyclical result does not apply in general, and can indeed flip over depending on the interplay between the size of the shock, the demand level observed in the last collusive period and the market variable being set by firms. More precisely, the larger the shock the higher the tendency towards the emergence of a procyclical pricing pattern, as the natural countercyclical tendency due to competitive behaviour is offset by the larger market size, thereby increasing the Nash equilibrium price. At the same time, as the difference between the pre-shock state of demands disappears, we observe the arise of countercyclicality, as the model takes an increasingly R\&S-like flavour.

Although we do not explicitly model partial collusion, our results suffice to imply that, if post-shock noncooperative pricing exhibits procyclicality, then by continuity - and, for any given structure of firms' intertemporal preferences - any post-shock partially collusive price (up to the new monopoly price level) which could be sustained by firms is necessarily procyclical as well.

An additional motivation of our paper can be found in the link with the related literature on mark-up cyclical properties, which has relevant macroeconomic implications. ${ }^{2}$ Although a considerable number of contributions points towards countercyclicality, ${ }^{3}$ the empirical literature on mark-up cyclical behaviour is not unambiguous. Donowitz et al. (1986, 1988) find evidence on procyclicality in the US; Chirinko and Fazzari (1994) use a dynamic factor model to estimate markups, finding that they are procyclical in nine of the eleven 4-digit industries they analyze. Updating Bils' (1987) analysis in favor of countercyclicality - with more recent and richer data, Nekarda and Ramey (2010) find that all measures of markups are either procylical or acyclical.

\footnotetext{
${ }^{2}$ In imperfectly competitive settings, the size of the government spending multiplier is increasing function of mark-up countercyclicality but decreasing function of its procyclicality (Hall 2009, Woodford 2011)

${ }^{3}$ See Martins et al (1996) on OECD, Chevalier et al. (2003) on the US, Portier (1995) on France.
} 
The rest of paper is structured as follows. Section 2 lays out a simplified version of the acquired model, delivering the traditional $R \& S$ results. Sections 3 and 4 insert our modifications and characterises equilibrium prices under price- and quantity-setting behaviour, respectively. Section 5 summarizes our results by carrying out a comprehensive analysis of price cyclicality in the post-shock period only, while section 6 looks at the long-run cyclical properties of pricing over time. Section 7 concludes.

\section{The theoretical status-quo}

The following is a simplified version of Rotemberg and Saloner's (1986) setup, in which we focus on the behaviour of a cartel formed by two firms, without further loss of generality. ${ }^{4}$ As in their paper, we consider an oligopolistic market with $n \geq 2$ single-product firms, over an infinite horizon. Time $t$ is discrete, with $t=0,1,2, \ldots \infty$, and the demand function pertaining to firm $i$ at any time $t$ is $q_{i t}=f_{i}\left(p_{i t}, \mathbf{p}_{-i t}\right)$, where $q_{i t}$ and $p_{i t}$ are firm $i$ 's output and price, respectively, and $\mathbf{p}_{-i t}$ is the vector of the rival firms' prices. The function $f_{i}\left(p_{i t}, \mathbf{p}_{-i t}\right)$ is assumed to be at least quasi-concave in $p_{i t}$, and, if products are substitutes in demand, $\partial f_{i}\left(p_{i t}, \mathbf{p}_{-i t}\right) / \partial p_{j}>0$ for all $j \neq i$. Firms have identical technologies represented by the cost function $\Gamma_{i}=c q_{i}$, with $\sigma_{t}>c \geq 0$. The profit function of the individual firm is $\pi_{i t}=\left(p_{i t}-c\right) q_{i t}$ at any $t . \sigma_{t}$, which measures the reservation price, is stochastic, and in each period can take one of two values, $a>b>0$, with probabilities $\mathfrak{p}(a)=m$ and $\mathfrak{p}(b)=1-m$, and $m \in[0,1]$.

We focus our attention on the situation in which firms aim at colluding along the frontier of monopoly profits. The supergame unravels following the rules of Friedman's (1971) perfect folk theorem, whereby any unilateral deviation from the collusive path is punished by a permanent reversal to the

\footnotetext{
${ }^{4}$ This exposition relies on (and slightly generalises) the simplified version of the countercyclical pricing model in Tirole (1988, pp. 248-250). It is formally equivalent to (but more manageable than) the linear model adopted in Rotemberg and Saloner (1986, p. 396, expressions (8-9)).
} 
Nash equilibrium of the constituent stage game forever (the so-called grim trigger strategy). As in Rotemberg and Saloner (1986), suppose firms set prices after having observed the state of demand (either $a$ or $b$ ).

At any $t$, collusion delivers the individual expected cartel profit:

$$
E \pi^{C}=m \pi^{M}(a)+(1-m) \pi^{M}(b)
$$

where $E$ denotes expected values, superscript $C$ stands for cartel and $\pi^{M}\left(\sigma_{t}\right)=$ $\Pi^{M}\left(\sigma_{t}\right) / n, \sigma_{t}=a, b$, is the per-period symmetric share of monopoly profits $\Pi^{M}\left(\sigma_{t}\right)$ accruing to each firm in the cartel phase, given the realization of the demand state $\sigma_{t}$. As in Rotemberg and saloner (1986), we pose that if a firm contemplates the possibility of deviation, it does so in a period of high demand, obtaining deviation profits $\pi^{D}(a)$ in that period. Such deviation at time $t$ is punished via the infinite Nash reversion from $t+1$ to doomsday. Taking into account the two possible states of demand and their respective probabilities, the expected per-period Nash profits amount to

$$
E \pi^{N}=m \pi^{N}(a)+(1-m) \pi^{N}(b)
$$

Assuming firms share identical time preferences measured by a symmetric and time-invariant discount factor $\delta \in(0,1)$, the stability of price collusion requires $\delta$ to meet the following necessary and sufficient condition:

$$
E \pi^{C} \sum_{t=0}^{\infty} \delta^{t} \geq \pi^{D}(a)+E \pi^{N} \sum_{t=1}^{\infty} \delta^{t}
$$

which is satisfied by all

$$
\delta \geq \frac{\pi^{D}(a)-E \pi^{C}}{\pi^{D}(a)-E \pi^{N}} \equiv E \delta^{*} \in(0,1) .
$$

If a favourable shock $\varepsilon>0$ occurs in state $a$ (while leaving state $b$ unaffected) and exerts permanent effects, the high demand state becomes $\widehat{a}=a+\varepsilon>$ $a>b$. Accordingly, (4) becomes

$$
\delta \geq \frac{\pi^{D}(\varepsilon)-E \pi^{C}(\varepsilon)}{\pi^{D}(\varepsilon)-E \pi^{N}(\varepsilon)} \equiv E \delta^{*}(\varepsilon)
$$


and, as shown in Rotemberg and Saloner (1986, pp. 394-97), $\partial \delta^{*}(\varepsilon) / \partial \varepsilon>0$. This property indicates that the critical threshold of the discount factor stabilizing full collusion increases with the good state. This is one of the elements leading to the (by now classical) interpretation of this model, according to which firms should collude less if demand gets higher, as the size of the market ensures high profits anyway, and this suggests the idea of countercyclical pricing.

This is certainly true if products are homogeneous, in which case there exists a single market demand function $Q=F(p)$ and the Nash punishment involves marginal cost pricing. If some degree of differentiation is present, however, the price at the Nash equilibrium will be somewhere above marginal cost and below the monopoly price firms would set were they able to sustain full collusion in state $\widehat{a}$, but not necessarily below the monopoly price corresponding to state $a$, let alone state $b$. Thus, the cyclical properties of price must be assessed comparing the price charged after the occurrence of the shock with the price actually charged before the occurrence of the demand shock disrupting the collusive path. Whenever the former is greater (smaller) than the latter, we observe a procyclical (countercyclical) pattern. In what follows, we will conduct this type of analysis both under price (section 4 ) and quantity (section 5) competition, under the condition $\delta \in\left(0, E \delta^{*}(\varepsilon)\right)$, whereby firms are unable to to meet the requirement for the stability of collusion, given the new level of the high demand state after the shock.

\section{Bertrand behaviour}

We model an oligopoly with product differentiation à la Singh and Vives (1984). If firms are price setters, the relevant direct demand function for variety $i$ in any period $\tau \geq t$ is

$$
q_{i}=\frac{\widehat{a}}{1+s(n-1)}-\frac{p_{i}[1+s(n-2)]-s \sum_{j \neq i} p_{j}}{(1-s)[1+s(n-1)]}
$$

in which parameter $s \in(0,1]$ measures the representative consumer's preference for variety, and therefore is an inverse measure of the degree of product 
differentiation between any two varieties. Parameter $\widehat{a}=a+\varepsilon$ is the vertical intercept of variety $i$ 's demand after a positive shock hits the high demand state, leaving state $b$ unaffected. For the sake of simplicity, in the ensuing analysis we stipulate that, if indeed firms are unable to collude on the frontier of monopoly profits in state $\widehat{a}$, they play the symmetric non cooperative Nash equilibrium price of the stage game. Each firm sets $p_{i}$ so as to maximise the single-period profit function $\pi_{i}=\left(p_{i}-c\right) q_{i}$. The relevant first order condition (FOC) is

$$
\frac{\partial \pi_{i}}{\partial p_{i}}=\frac{(a+\varepsilon)(1-s)-\left(2 p_{i}-c\right)[1+s(n-2)]+s \sum_{j \neq i} p_{j}}{(1-s)[1+s(n-1)]}=0
$$

which, under the symmetry condition $p_{i}=p_{j}=p$ for all $i, j$, delivers the Bertrand-Nash equilibrium price:

$$
p^{B N}(\varepsilon)=\frac{(a+\varepsilon)(1-s)+c[1+s(n-2)]}{2+s(n-3)}
$$

This must be compared to the cartel prices the same firms have practiced along the collusive path up to $t-1$, i.e., either $p^{M}(a)=(a+c) / 2$ or $p^{M}(b)=$ $(b+c) / 2$, depending of the observed state of demand.

The minimalistic condition for observing a procyclical price behaviour after the positive demand shock is the following. If the state at $t-1$ has been $b$, reverting to the Nash equilibrium strategy yields nonetheless an increase in price provided that $p^{B N}(\varepsilon)>p^{M}(b)$, i.e.,

$$
\frac{2(a+\varepsilon)(1-s)+c(n-1) s-b[2+s(n-3)]}{2[2+s(n-3)]}>0
$$

which is satisfied by all

$$
\varepsilon>\max \left\{0, \frac{b[2+s(n-3)]-2 a(1-s)-c(n-1) s}{2(1-s)}\right\}
$$

with

$$
\frac{b[2+s(n-3)]-2 a(1-s)-c(n-1) s}{2(1-s)}>0
$$

for all

$$
b \in\left(b_{B} \equiv \frac{2 a(1-s)+c(n-1) s}{2+s(n-3)}, a\right)
$$


since

$$
\frac{2 a(1-s)+c(n-1) s}{2+s(n-3)}>c \forall a>c \text { and } s \in(0,1) .
$$

The foregoing analysis boils down to the following:

Lemma 1 If the state of demand was $b$ at $t-1$ and becomes $a+\varepsilon$ at $t$, the reversion to Bertrand-Nash pricing implies a procyclical price pattern for all

$$
\varepsilon>\max \left\{0, \frac{b[2+s(n-3)]-2 a(1-s)-c(n-1) s}{2(1-s)}\right\} .
$$

In the remainder of the parameter space, the price pattern is countercyclical.

It is worth noting that Lemma 1 entails that if $b$ is sufficiently lower than $a$, then any positive shock affecting the high demand state produces a procyclical price behaviour, the switch from collusive to Bertrand-Nash pricing notwithstanding.

Now we can turn our attention to the case in which at $t-1$ firms were colluding in correspondence of the high demand state $a$. The relevant comparison is therefore between the same Bertrand-Nash equilibrium price $p^{B N}(\varepsilon)$ and the cartel price $p^{M}(a)$, with

$$
p^{B N}(\varepsilon)-p^{M}(a)=\frac{2 \varepsilon(1-s)-(a-c)(n-1) s}{2[2+s(n-3)]}>0
$$

for all

$$
\varepsilon>\frac{(a-c)(n-1) s}{2(1-s)}>0
$$

always, in the admissible range of parameters. This implies:

Lemma 2 If the state of demand was a at $t-1$ and becomes $a+\varepsilon$ at $t$, the reversion to Bertrand-Nash pricing implies a procyclical price pattern for all

$$
\varepsilon>\frac{(a-c)(n-1) s}{2(1-s)}
$$

The opposite holds for all $\varepsilon \in(0,(a-c)(n-1) s /[2(1-s)])$. 
It is easily checked that the condition appearing in Lemma 2 is more demanding than that identified by Lemma 1 . To do so, define

$$
\begin{gathered}
\varepsilon_{b}^{B} \equiv \frac{b[2+s(n-3)]-2 a(1-s)-c(n-1) s}{2(1-s)} \\
\varepsilon_{a}^{B} \equiv \frac{(a-c)(n-1) s}{2(1-s)}
\end{gathered}
$$

where superscript $B$ mnemonics for Bertrand, while the meaning of subscript $a, b$ refers to the demand state in the last stage of the collusive path. Then, observe that

$$
\varepsilon_{a}^{B}-\varepsilon_{b}^{B}=\frac{(a-b)[2+s(n-3)]}{2(1-s)}>0
$$

everywhere. Accordingly, we may claim:

Proposition 3 The condition $\varepsilon>\varepsilon_{a}^{B}$ suffices to ensure that the reversion to Bertrand-Nash behaviour involves a procyclical price pattern irrespective of the demand state realised in the last period of the cartel path.

Obviously, $\varepsilon_{a}^{B}$ is independent of $b$. The graph of $\left\{\varepsilon_{a}^{B}, \varepsilon_{b}^{B}\right\}$ in the space $(b, \varepsilon)$ is drawn in Figure 1. In area $I$, in which $\varepsilon>\varepsilon_{a}^{B}$, procyclical BertrandNash pricing obtains at $t$ for all $b \in(c, a)$, irrespective of whether the state at $t-1$ was $a$ or $b$. In area $I I$, in which $\varepsilon \in\left(\varepsilon_{b}^{B}, \varepsilon_{a}^{B}\right)$ procyclicality is observed at $t$ only if the state of demand at $t-1$ was $b$. Finally, in area $I I I$, the pricing behaviour at the Bertrand-Nash equilibrium is countercyclical. 
Figure 1 Critical shock levels in the space $(b, \varepsilon)$.

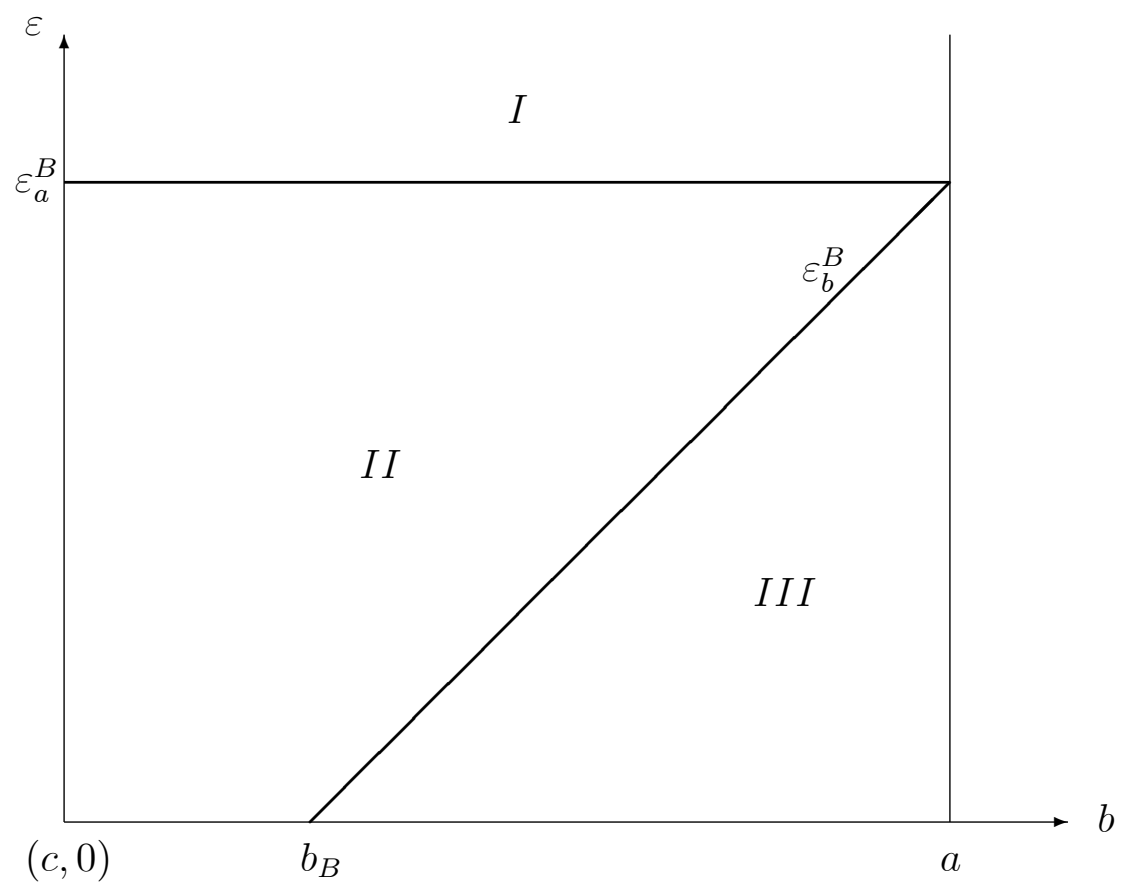

The intuition behind Proposition 3 is straightforward, as the necessary and sufficient condition for observing a price increase when collusion breaks down is more demanding if the state of demand was high in the last period of the collusive path. The next section replicates this analysis under Cournot behaviour.

\section{Cournot behaviour}

Here, the inverse demand for each product variety $i$ as soon as the shock takes place is

$$
p_{i}=\widehat{a}-q_{i}-s \sum_{j \neq i} q_{j}
$$


so that the resulting FOC writes as follows:

$$
\frac{\partial \pi_{i}}{\partial p_{i}}=a+\varepsilon-c-2 q_{j}-s \sum_{j \neq i} q_{j}=0
$$

for any vector of the rivals' output levels. The symmetric Cournot-Nash output solving (18) is

$$
q^{C N}(\varepsilon)=\frac{a+\varepsilon-c}{2+(n-1) s}
$$

giving rise to the following Cournot-Nash price, incorporating the shock:

$$
p^{C N}(\varepsilon)=\frac{a+\varepsilon+c[1+(n-1) s]}{2+(n-1) s}
$$

Proceeding as in the Bertrand case, one has to compare (20) with both collusive prices prevailing either instate $b$ or $a$ before the occurrence of the shock. Taking $p^{M}(b)$, one finds

$$
\begin{gathered}
p^{C N}(\varepsilon)>p^{M}(b) \Leftrightarrow \\
\frac{2(a+\varepsilon-b)-(b-c)(n-1) s}{2[2+s(n-1)]}>0
\end{gathered}
$$

which is satisfied by all

$$
\varepsilon>\max \left\{0, \frac{b[2+s(n-1)]-2 a-c(n-1) s}{2}\right\}
$$

with

$$
\frac{b[2+s(n-1)]-2 a-c(n-1) s}{2}>0
$$

for all

$$
b \in\left(b_{C} \equiv \frac{2 a+c(n-1) s}{2+s(n-1)}, a\right)
$$

Accordingly, we may claim:

Lemma 4 If the state of demand was $b$ at $t-1$ and becomes $a+\varepsilon$ at $t$, the reversion to the Cournot-Nash equilibrium implies a procyclical price pattern for all

$$
\varepsilon>\max \left\{0, \frac{b[2+s(n-1)]-2 a-c(n-1) s}{2}\right\} .
$$

In the remainder of the parameter space, the price pattern is countercyclical. 
Now suppose firms were colluding in state $a$ in the last period of the collusive path. In this case, $p^{C N}(\varepsilon)>p^{M}(a)$ for all

$$
\varepsilon>\frac{(a-c)(n-1) s}{2}
$$

such a threshold being positive everywhere. This implies:

Lemma 5 If the state of demand was a at $t-1$ and becomes $a+\varepsilon$ at $t$, the reversion to the Cournot-Nash equilibrium implies a procyclical price pattern for all

$$
\varepsilon>\frac{(a-c)(n-1) s}{2}
$$

The opposite holds for all $\varepsilon \in(0,(a-c)(n-1) s / 2)$.

Now, after defining

$$
\varepsilon_{b}^{C} \equiv \frac{b[2+s(n-1)]-2 a-c(n-1) s}{\varepsilon_{a}^{C} \equiv \frac{(a-c)(n-1) s}{2}}
$$

it is easily checked that

$$
\varepsilon_{a}^{C}-\varepsilon_{b}^{C}=\frac{(a-b)[2+s(n-1)]}{2}>0
$$

everywhere. The resulting picture is qualitatively equivalent to Figure 1. Consequently, we may formulate the following:

Proposition 6 The condition $\varepsilon>\varepsilon_{a}^{C}$ suffices to ensure that the reversion to Cournot-Nash behaviour involves a procyclical price pattern irrespective of the demand state realised in the last period of the cartel path.

The intuition here is analogous to the Bertrand case. We may now put together the two pieces of analysis carried out so far in order to take a general look at the cyclical pricing behaviour after the occurrence of a positive demand shock interrupting the cartel path. 


\section{A comprehensive look at price cyclicality}

From expressions (16) and (26), there emerges that $\varepsilon_{b}^{B}>\varepsilon_{b}^{C}$ and $\varepsilon_{a}^{B}>\varepsilon_{a}^{C}$ in the whole space of parameters, while

$$
\operatorname{sign}\left\{\varepsilon_{b}^{B}-\varepsilon_{a}^{C}\right\}=\operatorname{sign}\left\{\frac{(a-b)[2+s(n-3)]-(a-c)(n-1) s^{2}}{2(1-s)}\right\}
$$

so that $\varepsilon_{b}^{B}>\varepsilon_{a}^{C}$ for all

$$
b \in\left(b_{\varepsilon} \equiv \frac{a(1-s)[2+s(n-1)]+c(n-1) s^{2}}{2+s(n-3)}, a\right)
$$

The foregoing argument produces:

Proposition $7 \varepsilon_{a}^{B}>\varepsilon_{b}^{B}>\varepsilon_{a}^{C}>\varepsilon_{b}^{C}$ for all $b \in\left(b_{\varepsilon}, a\right)$, while $\varepsilon_{a}^{B}>\varepsilon_{a}^{C}>$ $\varepsilon_{b}^{B}>\varepsilon_{b}^{C}$ for all $b \in\left(c, b_{\varepsilon}\right)$.

Then, $b_{\varepsilon}$ can be compared with $b_{B}$ and $b_{C}$ appearing, respectively, in (12) and (24), to check that $b_{C} \geq b_{B}$ and $b_{\varepsilon} \geq b_{B}$ for all $s \in[0,1]$, while

$$
b_{\varepsilon}-b_{C}=\frac{(a-c)(n-1) s\left[(n-1) s^{2}-(n-5) s-2\right]}{[2+s(n-1)][2+s(n-3)]}
$$

which is positive for all

$$
s \in\left(\frac{n-5+\sqrt{n^{2}-2 n+17}}{2(n-1)}, 1\right]
$$

and negative in the remainder of the range of product substitutability. Hence, we have proved

Proposition $8 b_{\varepsilon} \in\left(b_{C}, a\right)$ for all

$$
s \in\left(\frac{n-5+\sqrt{n^{2}-2 n+17}}{2(n-1)}, 1\right]
$$

while $b_{\varepsilon} \in\left(c, b_{C}\right]$ for all

$$
s \in\left(0, \frac{n-5+\sqrt{n^{2}-2 n+17}}{2(n-1)}\right] .
$$


The critical expressions of the shock, $\left\{\varepsilon_{a}^{B}, \varepsilon_{b}^{B}, \varepsilon_{a}^{C}, \varepsilon_{b}^{C}\right\}$, can be drawn in the space $(b, \varepsilon)$, as in Figure 2, in which $b_{\varepsilon}>b_{C}>b_{B}$ since we have posed $s \in\left(\left(n-5+\sqrt{n^{2}-2 n+17}\right) /[2(n-1)], 1\right]$. The properties we are about to spell out in the following theorem are independent of the range of $s$ being considered, as well as the exact sequence of $\left\{b_{B}, b_{C}, b_{\varepsilon}\right\}$.

Figure 2 Critical shock levels in the space $(b, \varepsilon)$.

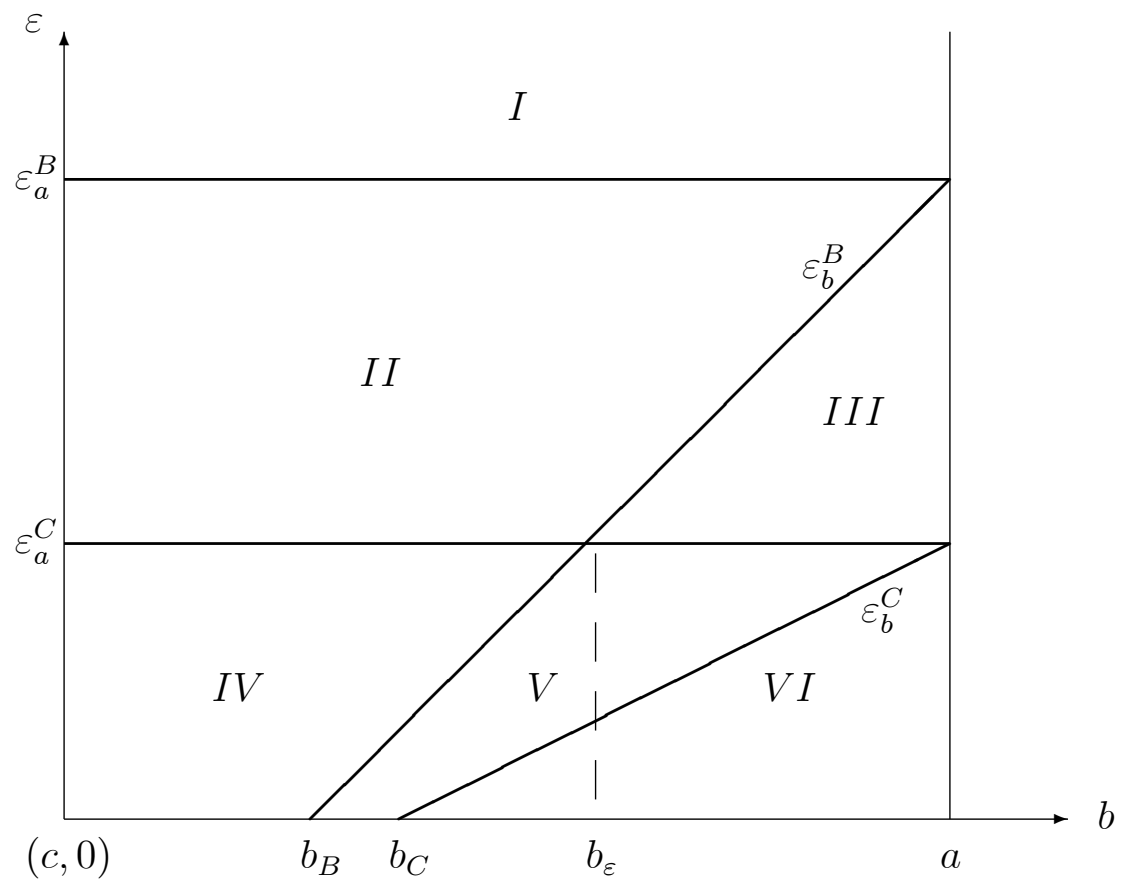

Theorem 9 The cyclical properties of non-cooperative Nash pricing at the Bertrand or Cournot equilibrium emerging after the abandonment of the collusive path in period $t$ are the following:

- In area $I$, procyclicality is observed for all $b \in(c, a)$, under both Bertrand and Cournot behaviour.

- In area II, countercyclicality emerges under Bertrand behaviour if the state of demand was a at $t-1$; otherwise, pricing is procyclical. 
- In area III, pricing is procyclical (resp., countercyclical) under Cournot (resp., Bertrand) behaviour, for any given state of demand at $t$.

- In area $I V$, pricing is procyclical (resp., countercyclical) under both Cournot and Bertrand behaviour, if the state of demand at $t$ was $b$ (resp., a).

- In area $V$, pricing is procyclical under Cournot behaviour if the state of demand at $t$ was b; otherwise, it is countercyclical.

- In area VI, countercyclicality is observed for all $b \in\left(b_{C}, a\right)$, under both Bertrand and Cournot behaviour.

The above Theorem summarizes our main results. We may provide a solid intuition by looking more closely at Figure 2. For any given state of demand in the collusive stage, as the size of the shock breaking down the cartel path increases (that is, we move along an imaginary vertical line starting at any point on the horizontal axis) the likelihood of observing procyclical pricing behaviour increases. This is crystal clear if, for instance, we draw the imaginary vertical line close to $a$, along the upper limit of the demand space: in such a case, as $\varepsilon$ increases, we move from complete countercyclicality (area $V I$ ) to countercyclicality only under price competition (area $I I I$ ) and then to complete procyclicality (area $I) .{ }^{5}$ The same pattern can be observed if we start from any point on the segment $(0, a)$. In other words, as the size of the positive demand shock disrupting collusion increases, the probability of observing procyclicality increases, as the tendency towards price reduction brought about by non-cooperative behaviour is increasingly offset by the higher post-shock state of demand firms face.

By the same token, if we draw an imaginary horizontal line starting from any point on the vertical axis lower than $\varepsilon_{a}^{B}$ (that is, we increase the preshock state of demand for any given shock size), we observe a strenghtening

\footnotetext{
${ }^{5}$ The fact that in area III countercyclicality is preserved only under Bertrand behaviour is easily understood, as price competition is intrinsically more intense than quantity competition, all else equal.
} 
of the countercyclical pattern. Also in this case the intuition is solid: as the pre-shock low state of demand collapses towards the high one, we loose one of the departures from traditional Rotemberg and Saloner framework (i.e. the alternative demand states before the shock) and therefore we are back to their standard countercyclical result.

\section{The price trend}

The foregoing discussion has focussed on the impact of the demand shock on the noncooperative price prevailing in the single period following the end of the cartel path, as compared to the collusive (monopoly) price characterising the last period of such path. Here we propose an analysis of the noncooperative price trend over $[t, \infty)$ against the cartel price over $[0, t-1]$. To this aim, we rely on probabilities $m$ and $1-m$, associated with states $a$ (as well as $a+\varepsilon)$ and $b$, respectively, to construct the following expressions:

$$
\begin{gathered}
p_{\tau}^{C}=m p^{M}(a)+(1-m) p^{M}(b) \\
p_{\tau}^{K N}=m p^{K N}(\varepsilon)+(1-m) p^{K N}(b)
\end{gathered}
$$

which measure the trend prices under collusion and fully noncooperative behaviour, respectively. In $(32), p^{K N}(\varepsilon)$ coincides, alternatively, with (8) or (20) and $K=B, C$ depending on the market variable being used by firms. Moreover,

$$
\begin{gathered}
p^{B N}(b)=\frac{b(1-s)+c[1+s(n-2)]}{2+s(n-3)} \\
p^{C N}(b)=\frac{b+c[1+s(n-1)]}{2+s(n-1)}
\end{gathered}
$$

Our exercise is based on the comparison between the average prices $p_{\tau}^{K N}$ and $p_{\tau}^{C}$ under price- and quantity-setting behaviour:

$$
\begin{gathered}
p_{\tau}^{B N}-p_{\tau}^{C}=\frac{2 m(1-s) \varepsilon-s(n-1)[m a+(1-m) b-c]}{2[2+s(n-3)]} \equiv \tau_{B} \\
p_{\tau}^{C N}-p_{\tau}^{C}=\frac{2 m \varepsilon-s(n-1)[m a+(1-m) b-c]}{2[2+s(n-1)]} \equiv \tau_{C}
\end{gathered}
$$


with

$$
\begin{gathered}
\tau_{B}>0 \Leftrightarrow \varepsilon>\frac{s(n-1)[m a+(1-m) b-c]}{2 m(1-s)} \equiv \varepsilon_{\tau B} \\
\tau_{C}>0 \Leftrightarrow \varepsilon>\frac{s(n-1)[m a+(1-m) b-c]}{2 m} \equiv \varepsilon_{\tau C}
\end{gathered}
$$

and obviously $\varepsilon_{\tau B}>\varepsilon_{\tau C}$ for all $s \in(0,1]$. It is also easily ascertained that $\varepsilon_{\tau B}$ and $\varepsilon_{\tau C}$ are both increasing in $b$, and same holds for their difference $\varepsilon_{\tau B}-\varepsilon_{\tau C}$. These two thresholds can be inserted in the graph appearing in Figure 2, to generate Figure 3, which has been drawn assuming $s \in\left(\left(n-5+\sqrt{n^{2}-2 n+17}\right) /[2(n-1)], 1\right]$, as before. In the region above $\varepsilon_{\tau C}$ (resp., above $\varepsilon_{\tau B}$ ), the price trend after firms revert to Nash pricing is procyclical under quantity-setting (resp., price-setting) behaviour. Since $\varepsilon_{\tau B}>\varepsilon_{\tau C}$ for all $s \in(0,1]$, we may formulate our final result:

Proposition 10 For all degrees of product substitutability, the region of the space $(b, \varepsilon)$ wherein the average Nash price after the shock is procyclical under Bertrand behaviour is a subset of the region where it is procyclical under Cournot behaviour.

That is, the necessary and sufficient condition for the procyclicality of Bertrand-Nash pricing is sufficient to ensure the arising of procyclicality under Cournot-Nash pricing (but not vice versa).

Proposition 10 has an additional relevant implication: if the trend of the Nash equilibrium pricing pattern is procyclical, then there will exist infinitely many degrees of partial collusion in prices or quantities which will generate procyclical collusive price trends even if full collusion along the frontier of industry profits cannot be sustained. This consideration alone, without a formal proof, reveals:

Corollary 11 If the Nash equilibrium price trand is procyclical, then any $\delta \in\left(0, E \delta^{*}(\varepsilon)\right)$ allows firms to achive a degree of partial collusion whose price trend which is procyclical as well, as it lies everywhere above the Nash equilibrium trend itself. 
Figure 3 Impact effect and price trend in the space $(b, \varepsilon)$.

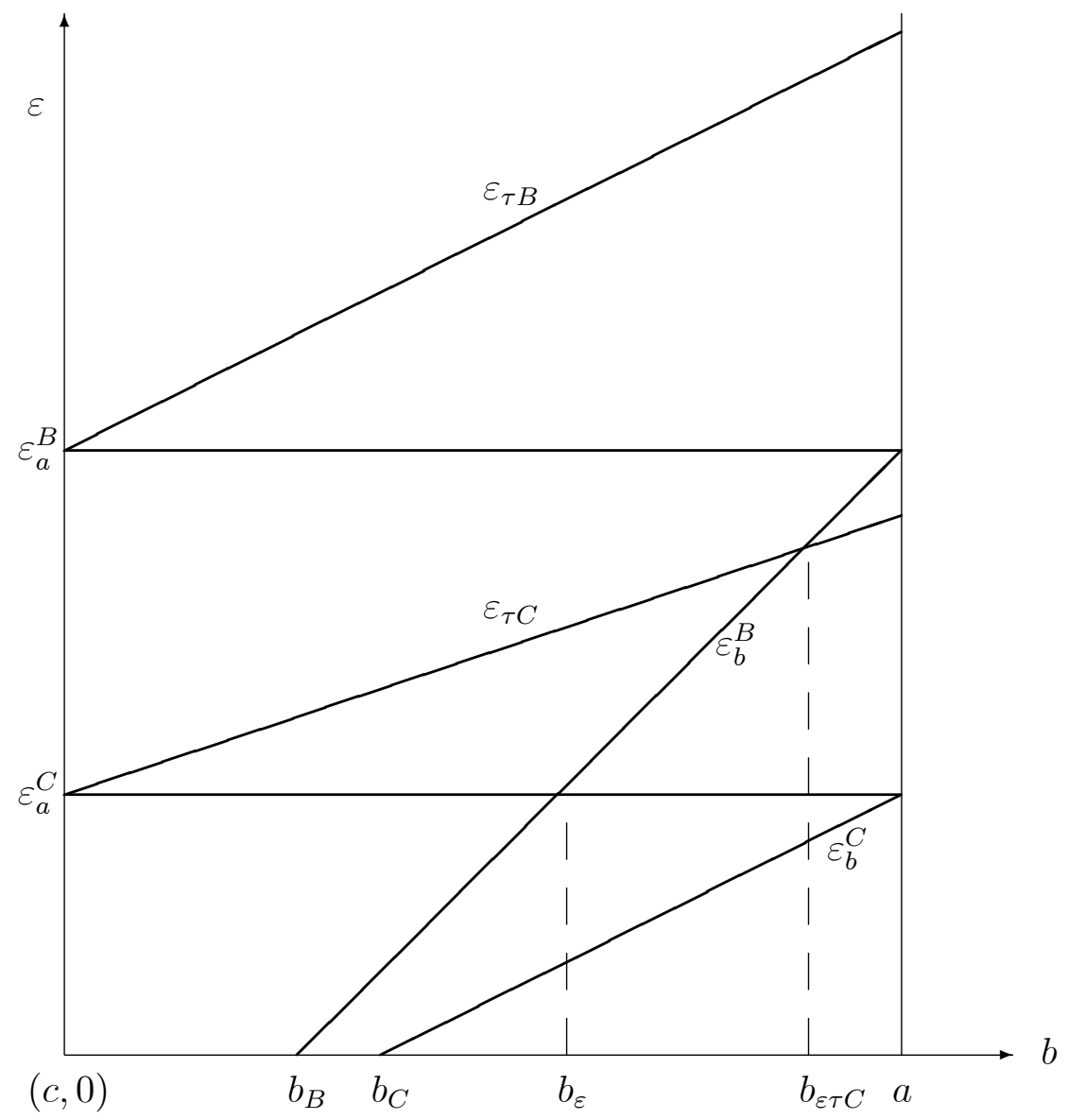

\section{Concluding remarks}

We have taken a new look at the pricing behaviour of oligopolistic firms when a positive demand shock occurs, breaking a form implicitly collusive agreement. We have shown that when the traditional Rotemberg and Saloner (1986) setting is extended so as to take explicitly into account the effect of the 
shock itself on the post-shock noncooperative equilibrium price, the standard countercyclical price result does not necessarily hold in general. The size of the cyclical fluctuation and the pre-shock demand state (along with the degree of product differentiation and the size of the market) play a key role in shaping the prices' response to the cycle. If the demand shock is large enough, or if the shock hits a relatively low state of demand, a procyclical pattern is likely to emerge. As our analysis look at the Nash competition (both under Cournot and Bertrand settings) after the shock, our procyclical results are valid for any degree of partial collusion firms might be able to sustain on the basis of their time preferences, up to the new monopoly frontier.

A more comprehensive analysis of pricing cyclical properties can have relevant implications for other dimensions of economic analysis. Procyclical prices - with marginal cost being constant or not more procyclical than prices - imply procylical mark-ups, with crucial consequences on the size of the government spending multipliers, as shown by Hall (2009), Christiano et al (2011) and Woodford (2011). For this reason, further research on the topic is required. 


\section{References}

[1] Bagwell, K. and R. Staiger (1997), "Collusion Over the Business Cycle", RAND Journal of Economics, 28, 82-106.

[2] Bils, M., (1987), "The Cyclical Behavior of Marginal Costs and Price", American Economic Review, 77, 838-55.

[3] Chevalier, J.A., A.K. Kashyap and P.E. Rossi (2003), "Why Don't Prices Rise During Periods of Peak Demand? Evidence from Scanner Data", American Economic Review, 93, 15-37.

[4] Chirinko, R.S. and M. Fazzari (1994), "Economic Fluctuations,Market Power and Returns to Scale: Evidence from Firm-Level Data", Journal of Applied Econometrics, 9, 509-13.

[5] Christiano, L., M. Eichenbaum and S. Rebelo (2011), "When is the Government Spending Multiplier Large?", Journal of Political Economy, 119, 78-121.

[6] Deneckere, R. (1983), "Duopoly Supergames with Product Differentiation", Economics Letters, 11, 37-42.

[7] Donowitz, I.R., G. Hubbard and B.C. Petersen (1986), "Business Cycles and the Relationship Between Concentration and Price-Cost Margins", Rand Journal of Economics, 17, 1-17.

[8] Donowitz, I.R., G. Hubbard and B.C. Petersen (1988), "Market Structure and Cyclical Fluctuations in US Manufacturing", The Review of Economics and Statistics, 70, 55-66.

[9] Fabra,N., (2006), "Collusion with Capacity Constraints Over the Business Cycle", International Journal of Industrial Organization, 24, 69-81.

[10] Friedman, J.W. (1971), "A Non-Cooperative Equilibrium for Supergames", Review of Economic Studies, 28, 1-12. 
[11] Friedman, J.W. and J.-F. Thisse (1993), "Partial Collusion Fosters Minimum Product Differentiation", RAND Journal of Economics, 24, 63145 .

[12] Hall, R. (2009), "By How Much does GDP Rises if the Government Buys More Output?", Brookings Paper on Economic Activity, Fall 2009, 183231.

[13] Haltiwanger, J. and J. Harrington (1991), "The Impact of Cyclical Demand Movements on Collusive Behaviour", RAND Journal of Economics, 22, 89-106.

[14] Knittel, C. and J. J. Lepore (2010), "Tacit Collusion in the Presence of Cyclical Demand and Endogenous Capacity Levels", International Journal of Industrial Organization, 28, 131-144.

[15] Lambertini, L. (1997), "Prisoners' Dilemma in Duopoly (Super)Games", Journal of Economic Theory, 77, 181-91.

[16] Majerus, D. (1988), "Price vs Quantity Competition in Oligopoly Supergames", Economics Letters, 27, 293-97.

[17] Martins, J., S. Scapetta and D. Pilat (1996), "Markup Pricing, Market Structure and the Business Cycle", OECD Economic Studies, 27, 71105.

[18] Nekarda, C. and V. Ramey (2010), "The Cyclical Behavior of the PriceCost Markup", mimeo, University of California, San Diego.

[19] Portier, F. (1995), "Business Formation and Cyclical Markups in the French Business Cycle", Annales d'Economie et de Statistique, 37, 41140 .

[20] Raith, M. (1996), "Product Differentiation, Uncertainty and the Stability of Collusion", STICERD discussion paper EI/16, LSE, London. 
[21] Ross, T.W. (1992), "Cartel Stability and Product Differentiation", International Journal of Industrial Organization, 10, 1-13.

[22] Tirole, J. (1988), The Theory of Industrial Organization, Cambridge, MA, MIT Press.

[23] Woodford, M., (2011), "Simple Analytics of the Government Expenditure Multiplier", American Economic Journal: Macroeconomics, 3, $1-35$. 


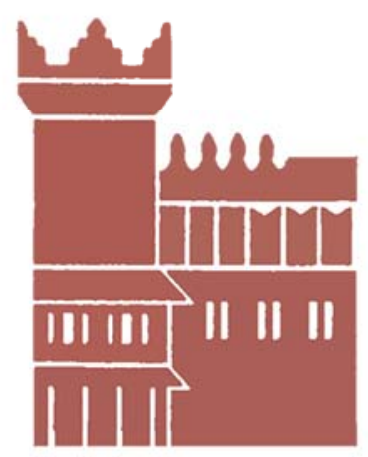

Alma Mater Studiorum - Università di Bologna DEPARTMENT OF ECONOMICS

Strada Maggiore 45

40125 Bologna - Italy

Tel. +39051 2092604

Fax +390512092664

http://www.dse.unibo.it 